International Journal of Instruction

e-ISSN: 1308-1470 • www.e-iji.net

Article submission code

20200205075257

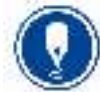

January $2021 \bullet$ Vol.14, No.1

p-ISSN: 1694-609X

pp. 709-726

Received: 05/02/2019

Revision: 24/07/2020
Accepted: 15/08/2020

OnlineFirst:15/11/2020

\title{
Empowering Learners' Reflective Thinking through Collaborative Reflective Learning
}

\author{
Aizan Yaacob \\ Assoc. Prof., School of Education and Modern Languages, Universiti Utara Malaysia, \\ Malaysia,aizan904@uum.edu.my \\ Ratnawati Mohd Asraf \\ Prof., Kuliyyah of Education, International Islamic University, Malaysia, \\ ratnawati@iium.edu.my
}

\section{Raja Maznah Raja Hussain}

Prof., Instructional and Learning Technologies Department, College of Education, Sultan Qabus University, Oman, rajamaznah@squ.edu.om

\section{Siti Noor Ismail}

Dr. School of Education and Modern Languages, University Utara Malaysia, Malaysia, siti.noor@uum.edu.my

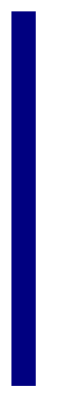

This paper is based on an action research that aimed to explore students' reflective thinking through reflective collaborative learning. Drawing on multiple methods collected through focus group interviews, reflections, and online feedback, this paper examines the processes in which students develop their collaborative reflective learning to provide peer feedback to improve each other's reflective writing. Two moments of intervention were set during the project to improve students' critical questioning and reflective writing. Overall, reflective thinking via collaborative reflective learning promotes knowledge sharing, enhances pedagogical methods and theory, increases understanding of learner characteristics, and fosters professional self-development.

Keywords: teacher education, reflective thinking, collaborative learning, ELT, action research

\section{INTRODUCTION}

Research suggests that reflective learning allows students not only to develop critical thinking skills but also to foster self- awareness of their own learning. Students engage in reflective learning by stepping back from their learning and analyze their experiences.

Reflective thinking was coined by Dewey (1933) and his work was taken up by Schon (1983) when he wrote about reflective practice in education and other professions. Since then, there has been a shift towards an interest in reflective thinking and many studies

Citation: Yaacob, A., Mohd Asraf, R., Hussain, R. M. R. \& Ismail, S. N. (2021). Empowering Learners' Reflective Thinking through Collaborative Reflective Learning. International Journal of Instruction, 14(1), 709-726. https://doi.org/10.29333/iji.2021.14143a 
began to recognize the importance of critical and analytical thinking that teachers and students developed through reflective practice (Xiao, Clark, Rosson \& Caroll, 2008; Yang, 2009; Cordingley, Bell, Thomason \& Firth, 2005; Green, Kim, \& Marioni, 2007). Reflective thinking enables teachers not only to reflect on what, why and how things are done and to adapt, develop and improve his or her practices, but also develop their professionalism through critical introspection. Xiao et al. (2008) studied reflective thinking during collaborative learning activity and discovered that explanation underlying decisions during reflective activities helped the undergraduates to articulate their thoughts and ideas, explored the course concepts and engaged in higher order thinking. Yang (2009) claimed that critical reflection developed through blogs allows teachers and students to develop a deeper understanding of themselves and their teaching and learning. Blogs used in their study enhanced critical reflection and community of practice where the student teachers actively discussed teaching theories and their implications with their peers. Similarly, Larrivee (2008) posits that critical reflection is the distinguishing attribute of reflective practitioners. She explains that critical reflection merges from "critical inquiry, the conscious consideration of the ethical implications and consequences of teaching practice, with self-reflection, deep examination of personal beliefs, and assumptions about human potential and learning" (p.341). Practitioners who engage in self-reflection and critical inquiry normally consider ethical values and implications of their practices. They also re-examine their own personal beliefs and assumptions about human learning to make sense of the events in their own social contexts.

While reflective practice is becoming the favoured paradigm for continuing professional development in higher education (Clegg, Tan \& Saeidi, 2010; Larrivee, 2008), little is known about the complex process that reflective practitioners go through. Clegg at al. (2010) claimed that there is still insufficiently rigorous understanding of the process and too few descriptions documented what actually occurs. Moreover, teachers' voices on their reflective thinking of classroom practices are still under-researched. CochranSmith \& Lytle (1990) as cited in Spark-Langer \& Colton, 1991, p.41) claimed that the narrative part of reflection from the teachers particularly in dealing with their own interpretations of the professional decisions related to their own contexts are still missing.

\section{Background of the study}

Malaysia, like any other countries which focus on education reform, has given high priority to higher education which aims to create citizens who are trained, skilled and knowledgeable as evident in the Tenth (2011-2015) Malaysia Plan. As such, in developing the needed human capital, the National Higher Education Plan (2007-2010) outlines the desired human capital which include knowledge, personal and interpersonal attributes. Among the personal attributes are goal oriented, self-disciplined, confident, resilient, motivated, fiercely competitive, intellectually engaging and possess critical thinking skills (Lee Yen Abdullah \& Fauziah Md Taib, 2012).

While the Malaysian government is aspired to improve students' learning, lack of critical thinking remains a major concern among Malaysian educators. Issues such as 
students having lack of critical thinking skills, not self-directed and not reflective are not new. Evidences collected from students' reflections indicated that students have not achieved a critical level of reflection and most of them were not self- regulated learners (Yaacob, Walters, Md Ali, Shaik Abdullah \& Walters, 2014; Boon Pong Yin \& Wee Kok Leng, 1982). In fact, only a few studies of the reflective writing process, as used by teachers were recorded (Subramanian, 2012; Yaacob et al., 2014). Yaacob et al. (2014) who conducted a study on 37 English Language Teaching (ELT) teacher trainees from a Malaysian university found that students demonstrated technical and practical level of thinking, but rarely rose to the critical level of reflection. Technical level reflection focuses on the teacher's experience and what works in his or her own classroom which mainly concerns success or failure of tools and techniques employed by the teacher himself or herself. Practical level reflection on the other hand, involves reflecting on the students' learning experiences and explaning the underlying assumptions, the methods used, the consequences of the strategies and the outcomes of the lesson. In addition, Boon Pong Yin \& Wee Kok Leng (1982) discovered that the majority of student teachers' reflections were at the technical level, far from the critical level. This is quite alarming because if the students and teachers do not reflect into their practices, they cannot change to good practice and they also cannot bring impact to teaching and learning. Furthermore, reflective writing has been little used and less studied in Malaysia, a nation determined to rapidly improve its educators and its educational system. Therefore, there is a need to examine students' voices and the processes that they went through during learning. We argue that reflective collaborative learning can enhance students' reflective thinking and improve their critical thinking over time.

This paper presents the findings from a study that explored students' reflective thinking through reflective collaborative learning based on an action research project for over one semester. It describes how students developed their community of practice by providing feedback to improve their reflections. We captured their reactions, reflections and online feedback to illustrate their reflective learning processes and how they benefitted from the collaborative reflective learning environment.

This study embarks on the following objectives:

1. To look into the best ways to give feedback to help post graduate students reflect at a critical level

2. To explore the learning processes involved in a reflective collaborative environment

3. To identify pedagogical change necessary to engage post graduate students in a reflective collaborative environment.

As this is part of a larger research project, this paper presents only the results of the second phase of the study which aims to identify the learning processes involved in a reflective collaborative environment. We discuss what the students learned from this collaborative reflective experience. 


\section{LITERATURE REVIEW}

\section{Reflective Thinking}

While numerous studies have attempted to explain the meaning of reflective thinking, there seems to be an inconclusive definition of it. Dewey (1933) claimed that reflection is an active process of challenging the comfortable, taken-for-granted parts of our professional self. It is challenging as it triggers thinking about the teaching and learning to solve a problem. Normally, the problem was brought about by a moment of doubt. Schon (1983) on the other hand, was interested to know what competent professionals know and how they acquire the knowledge as they become reflective practitioners. Schon's reflection-in-action and reflection-on-action, helped teachers to plan a better lesson which will have an impact on students' learning. Sometimes, teachers reflect in the midst of an action without interruption of the activity or event, while some other times they reflect after the event. Reflecting-in-action serves to reshape what one is doing while he or she is doing it. Meanwhile, reflection-on-action evolves from the limitations occurred in reflection-in-action (Schon, 1983).

Sparks-Langer \& Colton (1991) presented three important elements of understanding and studying teachers' reflective thinking which include the cognitive element (which describes how teachers process information and make decision); the critical element (focuses on the substance that drives the thinking-experiences, goals, values and social implications); and teacher narratives (teachers' own interpretations of the events that occur within their particular contexts) (p. 37). As for the cognitive element of reflection, the writers referred to Shulman's (as cited in Spark-Langer \& Colton, 1991) definition of pedagogical content knowledge which consists of the following: 1) content knowledge (content or subject matter, 2) pedagogical methods and theory, 3) curriculum, 4) characteristics of learners, 5) teaching context and 6) educational purposes, ends and aims. In the second element, they explained the Critical Theory perspective which posits knowledge as socially constructed by surrounding culture, context, customs and historical era. Finally, the third element includes teacher narratives using Action Research which takes into account teacher voices in relaying interpretations of classroom decisions they have made. These three abovementioned elements are used as a framework into understanding teachers' reflective thinking in this study.

\section{Related Studies on Collaborative Reflective Thinking}

Many studies have examined the potential benefits of reflective thinking in collaborative activity (Xiao et al., 2008). Many have used reflective thinking in health care sector (Fakude et al., 2014; Morrow, 2009) while others examined it in teacher education (Harris \& Bretag, 2010; Green et al.,2007; Cordingley et al.,2005). These studies indicate that collaborative inquiry is a powerful tool to develop reflective capacity and facilitate ownership of one's own learning.

In education, many studies have shown positive impact of reflective thinking on teaching and learning (Green, et al.2007; Cordingley et al. 2005; Harris \& Bretag, 2003). Green et al. (2007) discovered that participation of teacher educators in a faculty 
reflection group affected members' views of their teaching and learning. They reported that they learned and discussed personal goals through their collaboration, and they also identified strategies to achieve those goals. Similarly, Cordingley et al., (2005) examined the impact of collaborative continuous professional development (CPD) on classroom teaching and learning and discovered that it was linked with improvements in teaching and learning. Teachers were reported to have developed greater selfconfidence, enhanced beliefs about having the power to make a difference in their pupils' learning, developed enthusiasm for collaborative learning and had greater commitment to changing practice. Students reported having improvements in performance, motivation to learn, better organization of work and used collaboration as a learning strategy. In addition, Harris \& Bretag (2003) discovered that in an undergraduate management ethics course, a cycle of reflection and revision can be used in the development of curriculum and teaching methods as well as increase in quality learning outcomes.

In addition, peer supported reflective practice was also found to be useful in developing reflective practice among mentors, teachers and pre-service teachers (Bell,2001; Vidmar,2005; Kullman,1998). Kullman (1998) used peer supported reflective practice among mentors. He claimed that the purpose of mentoring was to help student teachers to develop reflective practice. As such, in his study, the use of role play which was designed to help mentors practice giving post-observation feedback proved to be useful in improving the model of mentoring. Bell (2001) also found that supported reflective practice which includes feedback given on observed teaching and feedback on reflection is effective in providing improvements to teaching practice. She contends that peer supported reflective practice helped pre-service teachers develop self- confidence and apply theory-in-use and ongoing professional development. In addition, Vidmar (2005) used reflective peer coaching to promote self-assessment and collaboration for better teaching and learning among pre-service teachers. Reflective peer coaching in his study which involved 10 minutes planning conversation prior to actual lesson, and a 10 minutes reflective conversation after the lesson helped to build self-awareness and selfassessment of teaching.

With the advancement of technology, there has been a great interest in exploring collaborative reflective learning online (Ruhleder \& Twidalem, 2000; Wheeler, 2009; O'Brien, Soibelman \& Elvin, 2003; Punthambekar, 2006; Nicholson \& Bond, 2003). Wheeler's (2009) study showed that blogs and wikis created new virtual learning spaces in teacher training programmes when the teacher trainees were asked to reflect on the strengths and weaknesses of these approaches. This provided evidence that Web 2.0 could be used to create collaborative and reflective learning spaces among teacher trainees. In a similar vein, Nicholson \& Bond (2003) who examined the use of an electronic discussion board to enhance collaborative reflection and professional community building among 17 pre-service teachers discovered numerous benefits associated with students improved learning. They revealed that the electronic discussion board was used to share experiences and ideas through discussions. It is argued that online learning can create a rich cognitive presence capable of supporting higher order thinking. 


\section{METHODS}

\section{Research Design}

This study was conducted using an Action Research design (Zuber-Skerritt, 2001) which lasted for three months. Action research designs "are systematic procedures used by teachers (or other individuals in an educational setting) to gather quantitative and qualitative data to address improvements in their educational setting, their teaching and the learning of their students" (Creswell, 2013, p. 22). As the researchers were interested to examine the learning processes involved in reflective collaborative environment and to improve students' learning, action research is found to be the most appropriate method of inquiry. Action research processes involve acting, observing, reflecting and revising plan of actions conducted in series of cycles. The role of the researchers were as 'complete participant' whereby they were fully engaged with the students and established a good rapport with them. As a matter of fact, one of the researchers was their lecturer in this study. Therefore, the data were reported from an ' $\mathrm{emic}$ ' perspective (Fetterman, 2010).

\section{Participants}

13 post-graduate students who were taking their Master's degree in English Language Teaching at one of the public universities in the northern region of Malaysia took part in this study. The researchers used 'purposeful sampling' based on accessible case as proposed by Creswell (2013) who noted that a researcher 'may select ordinary cases, accessible cases or unusual cases' (p.100). The participants consisted of twelve (12) female and one (1) male student from different ethnic backgrounds: Malay, Indian and Thai, with teaching experience ranged between 1 and 20 years. They were divided into three groups based on a 'voluntary basis'. Table 1 below shows the profile of the participants in this study.

Table 1

Participants by race, gender and teaching experience

\begin{tabular}{llllc}
\hline Group & Codes & Race & Gender & Experience (years) \\
\hline 1 & Zain & Malay & M & $>5$ \\
\hline 1 & Janna & Indian & F & $<5$ \\
\hline 1 & Zue & Malay & F & $>5$ \\
\hline 1 & Naz & Malay & F & $<5$ \\
\hline 2 & Nana & Malay & F & $>5$ \\
\hline 2 & Iqah & Malay & F & $>5$ \\
\hline 2 & Linee & Malay & F & $>5$ \\
\hline 2 & Som & Thai & F & $>5$ \\
\hline 3 & Fina & Malay & F & $>5$ \\
\hline 3 & Thilla & Indian & F & $>5$ \\
\hline 3 & Anis & Malay & F & $>5$ \\
\hline Sarah & Etta & Malay & F & $<5$ \\
\hline
\end{tabular}

Key: > more than; < less than 


\section{The course}

SGDB 6013 ELT Professional Concerns Seminar is a course in Master of Education specializing in English Language Teaching (M.Ed (ELT). This seminar-led-course discusses important issues related to the English Language Teaching (ELT) such as teacher training, types of systems of schooling (private vs. public), management of ELT, status of English, status of teachers, and native versus non-native teachers of English. One of the learning outcomes of this student-led seminar is to allow students to reflect on their professional experiences. As part of the assessment, students are asked to write weekly reflections on issues discussed in class.

\section{Data Collection Methods}

Data were collected qualitatively from various sources such as focus group interviews, students' and researchers' reflections and online feedback. The following section details out the methods used.

\section{Focus Group Interviews}

Focus group interviews were conducted with the group members twice, at the beginning of the study to examine the problems they had with writing reflection and to analyse the nature of feedback practices, and at the end of the study after the intervention was conducted to investigate the extent in which the intervention improved their reflection. Students were allowed to select their own group members based on voluntary basis. The group interviews involved between four and five students (Bryman, 2001). The interviews lasted between half an hour to one hour in each session and they were recorded and transcribed verbatim for analysis.

\section{Students' and researchers' reflections}

Throughout this study, students were asked to write weekly reflection on English Language Teaching issues discussed in class, and posted it online for their group members to review. All in all, there were 27 reflections collected and analyzed. Researchers on the other hand, observed and reflected on the nature of feedback given by the students. This is crucial as they needed to identify the problems faced by the students and plan an appropriate technique or approach to remedy the problems. All in all, the researchers' reflections were collected before, during and after the intervention. The researchers also reflected after every analysis of the data in all the three phases.

\section{Online feedback}

Evidences from students' learning and participation during the in-class discussion and online were also collected for analysis. The students were encouraged to post their weekly reflection to the group members online either through Whatsapp, Facebook or email. The aim was to examine the nature of feedback given to their peers to improve reflective writing. Later, they had to comment on their friends' reflections for further improvement. In order to protect the group's privacy, only the group members could have access to the online postings and feedback. 


\section{Data Analysis}

The data in this study were analyzed using thematic coding based on concept-driven thematic analysis that also served as the outline of the analysis of the findings in this study. Braun and Clarke (2013, pp. 202-203) outline seven stages of thematic analysis which involved transcribing, reading and familiarizing, coding across the entire data set, searching for themes, reviewing themes and subthemes, defining and naming themes and finalizing analysis.

\section{Data Collection Procedures}

This Action Research involved series of cycles and it was carried out in three phases. In the first phase which was the problem identification stage, a focus group interview was conducted with the students to explore issues regarding writing reflection. Students were asked to write weekly reflection on the issues discussed in class. Then they posted it online for the researchers and peers to review. The researchers noticed that students had some difficulties in writing reflection as it has not been a common practice. As such, in the second phase interventions were carried out. Students were provided with some guidance in using Gibbs' Reflective Model (1988). As a matter of fact, two cycles of intervention were conducted: one was using Gibbs' Reflective Cycle (since they were unfamiliar with a systematic model in writing reflection) and the other one was teaching them the Socrates' Critical Questioning techniques as they could not provide critical evaluation of their peers' reflective writing. At this stage, the students and the researchers worked collaboratively to give feedback to their peers and improve their reflections. Finally, in the third phase which was the evaluation stage, another focus group interview with the participants was conducted to gather information about the overall process and to evaluate the effectiveness of the two- moment intervention and to identify challenges faced by them.

\section{Validity and Reliability}

Being aware of many ethical issues in qualitative inquiry, the researchers carefully discussed the issue of confidentiality and the right for withdrawal from this research (Braun \& Clarke, 2013) with the participants at the initial stage of this study. Researchers protected the anonymity of the participants by assigning pseudonyms to their names and explaining to them the purpose of this action research to improve their reflective writing and that the data would only be used for research purposes.

As action researchers are so involved in the process at a multiple level and in multiple roles, it is common for them to utilize critical friends (Anderson, Herr \& Nihlen, 1994) peer debriefing. They are usually peers or colleagues who are willing to debrief with the researchers, collaboratively making sense of the data. Herr and Anderson (2005) argued that critical friends are vital boards, to help researchers step back from the research to thoroughly understand what it is they are seeing and doing. Hence, in this study, peer debriefing with the other researchers were conducted after the data were analyzed. The debriefing process provided an external check and additional input to the research 
process particularly on the action plans. In addition, inter-rater reliability (Braun \& Clarke, 2013) is ensured by comparing and checking the coding made by two or more researchers.

\section{FINDINGS}

The findings in this study are presented thematically based on the focus group discussion and students' reflections.

\section{Reflective Thinking Via Collaborative Learning Promotes Knowledge Sharing}

Reflective collaborative environment fosters knowledge sharing among the participants. The students highlighted the development of knowledge sharing through collaborative activities and discussion. One of the students (Etta) mentioned that knowledge sharing was important in disseminating new input to other teachers to improve teaching and learning, while others (Zue and Janna) claimed that collaborative learning led them to apply theories to their current practices. Zue stated that she learned new theories by observing others in the group activities which was different from her previous learning.

"The knowledge sharing is important in spreading the new input for all the teachers to improve the teaching and learning process." (Etta)

I am 'changed' as previously I only know that I only learn through notes and theories but through this action research, I have tried to apply the theories and experience to observe diverse students' behaviours through the group work.” (Zue)

"I learnt how to use different principle and practice in class to teach different level of students. I have learnt many issues on ELT. I learnt a lot of approaches...I learnt to relate the different theories in my teaching." (Janna)

Collaborative learning is also seen as a platform for students to share new ideas for better understanding of any issues discussed in class. One of the students (Iqah) commented that peer feedback via collaborative learning helped her clarify her expectations, made her more open to criticism and improved her writing.

"Peer feedback helps a lot because we can share different perspectives over the particular issue. By looking at different angle, we can get better understanding about our expectations and be more open to be criticized. Peer feedback certainly helped me to improve my understanding of a certain topic. Last semester, peer feedback helped me to write better article review. People have different ideas and perspectives thus when we have peer feedback we are actually being exposed to sharing new ideas." (Iqah)

All in all, reflective collaborative learning provides an avenue for students not only to share new knowledge, theories and principles in Teaching English as a Second Language (TESL), but also to relate to their practices by observing what others did in their respective classrooms. As the group members consisted of a mixture of experienced and inexperienced teachers, the discussions on how new knowledge was used and implemented in other contexts somehow benefitted the inexperienced ones. 


\section{Reflective Thinking Via Collaborative Learning Enhances Pedagogical Methods and Theory}

The second theme emerged was that reflective collaborative learning enhanced pedagogical methods and theory. During the first phase of this action research the students were not able to give critical feedback to their peers and they had difficulty writing critical reflections. Therefore, during two moment-intervention, they were taught how to ask critical questions using Socratic Questioning Technique and to write reflection using Gibbs' Reflective Model.

Majority of the students reported they learned how to ask questions from Socratic Questioning technique (SQT). Nana said she should go easy on asking questions to her students, while Etta acknowledged that she had to improve on her questioning technique. Janna, on the other hand, stated that she learned both giving feedback using Socratic Questioning Technique and writing reflection based on Gibb's Reflective Model. Similarly, Sarah also stated that SQT helped her to 'understand deeper' the subject matter.

"I should take it easy in asking question by throwing question in simple manner". (Nana)

"I need to work on my questioning techniques". (Etta)

"Eventually, I learned to give feedback based on the Socrates questioning techniques. And, I have learnt to write reflection based on Gibb's cycle. I learnt something new" (Janna).

"(I) know how to use Socratic questioning by highlighting the things that I did not understand... for me the Socratic questioning is one of the tools that can make me understand deeper about something whether factual or by experience".(Sarah)

In summary, the data revealed that reflective collaborative learning increased students' awareness on pedagogical methods and theory which is consistent with Shulman's findings. The intervention strategies such as the Socratic Questioning Technique somehow enhanced their critical questioning and reasoning, while Gibb's reflective model provided guidance into writing better reflection.

\section{Reflective Thinking Via Collaborative Learning Increases Understanding Learners' Characteristics}

Understanding learners' characteristics is another important theme occured. The findings indicated that reflective thinking via collaborative learning increases understanding of learners' characteristics. The students in this study stated that they were more aware of their learners through collaborative exercises. Nana mentioned that through this activity, she learned to understand her students better and she also improvised her teaching to suit her students' needs. Iqah claimed that as a teacher, she needed to know her students first before teaching them.

"I understand my students better. I improvise my teaching." (Nana) 
"I need to know my students first before teaching them." (Iqah)

Collaborative activities provided them with opportunities to discuss the learners' characteristics. They brought in their classroom experiences in dealing with the learners and discussed the best method or technique to suit their learners' needs. This thinking will eventually help them to improve their teaching and learning.

\section{Reflective Thinking Via Collaborative Learning Fosters Self-Development}

Reflective thinking develops students' self - development. The students reported that they were more aware of themselves and their roles as teachers through reflective collaborative learning. They mentioned that they learned more about their strengths and weaknesses and they were concerned about the 21 st Century teacher qualities. Zue mentioned that she learned that she should be "resourceful, a role model, reflective, flexible, warm and caring" to her students while Zain stated that he became more aware of the 21st century teacher quality. Som, a Siamese teacher, on the other hand, expressed her happiness for being able to practise 'self-reflection' to assess her strengths and weakness.

"I have gained a better paradigm on teaching that I should be resourceful, a role model, reflective, flexible, warm and caring to my students to enable a good teaching. I have learned that there are always changes in the teaching field, thus we have to adapt and adopt wisely." (Zue)

"One thing I learned from this course is to give the opportunity to myself to have selfreflection. Through self-reflection I know my strength and weakness.” (Som)

"The course makes me concern about $21^{\text {st }}$ century teacher qualities emphasizing on improving our roles as a teacher.” (Zain)

\section{Motivated and reflective}

The participants also reported that they became more motivated as a teacher, more confident and more reflective. This reflective practice has somehow changed the way they acted.

"I am a new, and motivated teacher been exposed to the course”. (Anis)

"This experience changed the way I acted and now I am able to use and enhance my abilities". (Sarah)

This new experience has made them more reflective. Naz tried to make reflection her routine practice by reflecting after each class. Habit formation needs to be encouraged until it becomes engrained in the students' practice. In fact, she often discussed her actions with her mother who is an experienced lecturer. These reflection exercises made her more interested in improving her teaching in various situations and conditions.

"Yes I have problems in writing reflections in terms of relating the theories to my experience. However, this can be overcome if I make reflection or reflective thinking as a habit. I am trying to reflect myself after every class where before this was using my 
subconscious, but now I make it as a routine since my lecturers have suggested. I overcome the problem by verbalizing my problems, asking my mother of what she thinks about my actions since she is a much more experienced academician, it has helped me a lot. Apart from that, writing reflections in every class makes me feel the interest in improving myself in every class, it also has improved myself in terms af dealing with varieties of situations" (Naz).

Similarly, Nana tried to be more reflective by reflecting on her lessons and applying metacognitive strategies in teaching reading.

"I tried to be more reflective. I reflect on my lessons to help my students acquire English...applying metacognitive strategy especially in reading." (Nana)

"Another one is related to reflection writing. Previously I was aware of the benefits of reflection, but after being in this class...I am informed that it is extremely beneficial and fruitful. I should practice it no matter what".

(Anis)

\section{Critical when giving feedback}

The students also claimed that they became critical or analytical when giving feedback to their peers. Iqah said that she managed to think critically and was able to evaluate her own reflection, while Nana felt that she needed to think critically when giving constructive feedback. Nana elaborated that the reflective activities made her more aware of what she was reading and writing and she believed that with practice she would master the skill in giving and receiving feedback.

"I managed to think critically and this exercise makes me more able to give more comments on my reflection." (Iqah)

"To think critically and to give positive feedback, for improvement. So this will enable me to be a good reflective person." (Thila)

"Lastly giving and receiving feedback encourage me to be more analytical. I learn to be aware of what $i$ am reading and writing. This may be new to me but $i$ think with practice $i$ will improve myself in giving and receiving feedback". (Nana)

Open to Criticism

Finally, through reflective collaborative activities, the students stated that they have changed to become more open to criticism. Janna stated that she was more open to feedback and asked for clarification to improve her reflection.

"It makes me realize that I do have weaknesses and by receiving feedback it opens my eyes on what to improve and how to be a better writer". (Nana)

"I am open to all feedback and I ask for clarification on written feedback to help myself to develop and improve my reflection writing" (Janna)

In summary, awareness on roles and responsibility is important for professional development of these students. The findings indicated that they assessed their strengths and weaknesses, they developed shared understanding of their vision as 21 st century 
teachers which required them to adapt to changes in their roles and responsibility. Reflective thinking also helped them to become more motivated about their teaching profession, more reflective, critical, and open to criticisms.

\section{DISCUSSION AND CONCLUSION}

This paper reports the results of students' reactions and reflections of reflective thinking through reflective collaborative learning. The findings illustrate their reflective learning processes and how they benefitted from the collaborative reflective learning environment. Some conclusions drawn from this study are: reflective thinking via collaborative learning promotes knowledge sharing; enhances pedagogical methods and theory; increases understanding of learners' characteristics and fosters self-development.

Earlier studies have shown that reflective collaborative learning promotes knowledge sharing among students and enhances pedagogical methods and theory (Haris \& Bretag, 2003; Bell, 2001). The findings in this study also revealed that students shared knowledge about what worked in their classrooms and they questioned the complexity between theory and practice. They also offered solutions to the problems. By doing this, they became more aware of pedagogical methods and theories relevant to their ESL context. While Shulman's cognitive element of reflective thinking such as content knowledge, pedagogical content knowledge, understanding learner characteristics and self- development of the teachers were all evident in this study, the critical element which situated knowledge as socially constructed was not shown in the data. The students in this study did not reflect whether professional activity is equitable, just and respectful of persons, and they also did not analyze their personal action within wider socio-historical and politico-cultural contexts. This could be due to the fact that they are not trained to think beyond the classroom and the school settings. Furthermore, there is no platform for them to discuss issues beyond this level. Global mindedness is something that needs to be incorporated in the Malaysian education system and in teacher professional development programmes (Yaacob, Awang-Hashim, Valdez \& Yusof, 2019). As such, getting students to become critical thinker is still a goal to strive for in this context. Since this critical element is still missing in the students' reflection in this study, it is felt that students and teachers need to be trained to reflect based on socio-historical and politico-cultural contexts. Needless to say, future research should look into strategies to help students and teachers to write critical reflection by focusing on wider socio-historical and political-cultural contexts.

We have provided evidence that reflective collaborative learning fosters selfdevelopment (Ash \& Clayton, 2009; Nicol \& Macfarlane-Dick, 2006) whereby the students discussed their personal goals and values (Green et al., 2007), they developed greater self-confidence and motivation (Cordingley et al., 2005; Haris \& Bretag, 2003) and they worked towards an improvement in their teaching practice (Bell,2001; Vidmar, 2005). They learned to identify their strengths and weaknesses, they claimed that they changed to become more reflective, critical as a result of this collaborative exercises. They mentioned that collaborative feedback provided them with a learning space that enabled them to be reflective of themselves and their practices. Eventually, they became more open to criticism. During reflective collaborative processes, they collaborated with 
one another, they assessed their strengths and weaknesses and they developed shared visions. This is in line with the claims made by Ash and Clayton (2009: 30) who stated that, "Collaboration could be understood as an element of diversity learning, professional development, personal growth, or civic learning".

In the context of this study, diversity learning was achieved through communication with diverse others, professional development was acquired through team work while personal growth was obtained when assessing strengths and weaknesses and questioning personal values and work values. The findings are also supported by Nicol \& Macfarlane-Dick (2006) who stated that reflective collaborative feedback helped students take control of their learning and become self-directed learners. The participants in this study reported that, reflective collaborative learning is seen as a crucial way to facilitate students' development as independent learners who are able to monitor, evaluate, and regulate their learning. In the dynamic nature of reflective collaborative learning, both teachers and students learned through dialogue and participation in shared experiences (Carless et at., 2011) which lead to shared understanding as part of the development of communities of practice (Wenger, McDermott, \& Synder, 2002).

The findings also indicated that creating a safe learning environment is crucial for learning. In order to engage students to learn in a reflective collaborative environment, we discovered that online learning provided a safe learning space for them. The online learning environment made them feel secure to voice out their opinions about their learning. This is in congruent with earlier studies on the positive effect of online learning (Ruhleder et al., 2000; Wheeler, 2009; O’Brien et al., 2003; Punthambekar,2006; Nicholson \& Bond, 2003). Online learning created collaborative and reflective learning spaces which are not normally received in the classroom. The students learned to develop trust during collaboration, particularly when they were allowed to identify their own group members, whom they were most comfortable working with. They gave and received feedback from their peers, reflected on the comments and improved their reflective writing. In addition, collaborative environment online conducted via whatsapp, facebook or other media proved to be useful in providing students with a platform to share knowledge and ideas about the subject matter. This non- threatening environment enhanced collaborative learning among the participants. They provided support and encouragement to one another and they shared expertise in many aspects of teaching and learning. With the availability of technology, online feedback can be given anytime, anywhere and not just in formal face-to-face situation.

In conclusion, earlier studies have indicated that good teachers reflect on their practices (Dewey, 1933; Schon, 1983). We have provided evidence that students reflected during and after conducting an activity, however, they needed to be given a platform to do so. This is resonant with Mezirow (1990) who argues that reflection allows teachers to critically evaluate the current practice and to correct the distortions in their beliefs by questioning the usefulness of the instructions, and thinking ahead for the next step of action to ensure that learning is taking place. As one engages in reflection, not only one 
learns by asking questions, examining causality, contrasting theory with practice, but also deepens one's understanding by challenging conclusions, suggesting alternative perspectives and documenting learning by providing new understanding for evaluation. All of these transformative learning could be seen in this study. As a matter of fact, the feedback processes became more effective when they were done collaboratively whereby all the students provided support and encouragement to one another in their learning process. As such, reflective thinking has to be fostered among students and teachers to ensure quality teaching and learning.

\section{Funding}

This work was based on research supported by the Universiti Utara Malaysia through the Scholarship of Teaching and Learning Grant Scheme (Research ID: 3830). The writers would also like to thank the Research Management Centre, International Islamic University Malaysia, for the grant, P-RIGS18-025-0025, that made the publication of this work possible.

\section{REFERENCES}

Anderson, G.L., Herr, K. \& Nihlen, A.S. (1994). Studying your own school. Thousand Oaks, CA: Corwin.

Ash, S. L. \& Clayton, P. H. (2009). Generating, deepening and documenting learning: The power of critical reflection in Applied Learning. Retrieved from www.scholarworks.iupui.edu

Bell, M. (2001). Supported reflective practice: A programme of peer observation and feedback for academic teaching development. International Journal of Academic Development, 6(1), 26-39.

Braun, V. \& Clarke, V. (2013). Successful qualitative research. A practical guide for beginners. London: Sage Publications Ltd.

Bryman, A. (2001). Social research methods. Oxford: Oxford University Press.

Boon Pong Yin \& Wee Kok Leng. (2005). Facilitating reflection in education studies: a case study among pre service student teachers. Journal IPBA, 3(2),1-16.

Carless, D., Salter, D., Yang, M. \& Lam, J. (2011). Developing sustainable feedback practices. Studies in Higher Education, 36(4), 395-407.

Clegg, S., Tan, J. \& Saeidi, S. (2010).Reflecting or acting? Reflective practice and continuing professional development in higher education. Reflective Practice, 3(1), 131146.

Cordingley, P., Bell, M., Thompson, S. \& Firth, A. (2005). The impact of continuing professional development (CPD) on classroom teaching and learning. Review: How do collaborative and sustained CPD but not collaborative CPD affect teaching and learning. London, Institute of Education. Retrieved from: pdfs.semanticscholar.org 
Cresswell, J. W. (2013). Qualitative inquiry and research design: Choosing among five approaches. (3rd edition). London: Sage Publications, Inc.

Dewey, J. (1933). How we think: A statement of the relation of reflective thinking to the education process. Chicago: Henry Regnery.

Fakude, L. P., Le Roux, L., Daniels, F. \& Scheepers, N. (2014). Reflections of nursing students, lecturers and clinical supervisors in the Western Cape on large classes: Part 1 Contemporary issues in nursing. South African Journal of Higher Education, 28(6), 1762-1775.

Fetterman, D.M. (2010). Ethnography: Step by Step(3rd ed.). Thousand Oaks, CA: Sage

Gibbs, G. (1988). Learning by doing: A guide to teaching and learning methods. London: FEU.

Green, W.L., Kim, Y. \& Marioni, J.L. (2007). The reflection trio: A model for collaborative self-study in teacher education. KJEP, 4(1),41-58.

Harris, H. \& Bretag, T. (2003). Reflective and collaborative teaching practice: Working towards quality student learning outcomes. Quality in Higher Education, 9(2),179-185.

Herr, K. \& Anderson, G.L. (2005). The action research dissertation: A guide to faculty and students. Thousand Oaks, Calfornia: Sage.

Kullman, J. (1998). Mentoring and development of reflective practice: Concepts and context. System, 26(4), 471-484.

Larrivee, B. (2008). Development of a tool to assess teachers' level of reflective practice. Reflective Practice, 9(3), 341-360.

Lee Yen Abdullah, M.N. \& Md Taib, F. (2012). Governance reforms in public universities of Malaysia. Penang: USM Publications.

Malaysia Ministry of Higher Education. (2007). The National Higher Education Plan 2007-2010.

Mezirow, J. (1990). How critical reflection triggers transformative learning: Fostering critical reflection in adulthood. www.academia.edu.

Nicol, D.J. \& Macfarlane-Dick, D. (2006). Formative assessment and self-regulated learning: A model and seven principles of good feedback practice. Studies in Higher Education, 31(2), 199-218. Retrieved from: www.srhe.tandfonline.com.

Nicholson, S.A. \& Bond, N. (2003). Collaborative reflection and professional community building: An analysis of pre-service teachers' use of an electronic discussion board article. Journal of Technology and Teacher Education, 11(2), 259-279. 
O’Brien, W., Soibelman, L. \& Elvin,G. (2003). Collaborative design processes: An active and reflective-learning course in multidisciplinary collaboration. Journal of Construction Education, 8(2), 78-93.

Punthambekar, S. (2006). Analysing collaborative interactions: Divergence, shared understanding and construction of knowledge. Computers in Education, 47(3), 332-351.

Ruhleder, K. \& Twidalem, M. (2000). Effective collaborative learning on the web: Drawing on the master class. First Monday, 5/5. Retrieved from https://ojphi.org

Schon, D.A. (1983). The reflective practitioner: How professionals think in action. New York: Basic Books.

Spark-Langer, G.M. \& Colton, A.B. (1991). Synthesis of research on teachers' reflective thinking. Educational Leadership, March, 37-44.

Subramanian, M. (2012). Journal writing as a tool for teacher trainees: Reflection on teaching. Retrieved from: http://ipbl.edu.my.

The Tenth Malaysia Plan 2011-2015. The Economic planning unit. Prime Minister's Department, Putrajaya. Retrieved from:http://www.pmo.gov.my/dukumentasi attached/RMK/RMK10_Eds.pdf

Vidmar, D. J. (2005). Reflective peer coaching: Crafting collaborative self - assessment. Teaching Research Strategies, 20(3), 135-148.

Wenger, E., McDermott, R. \& Synder, W.M. (2002). Seven principles for cultivating communities of practice. From cultivating communities of practice: A guide to managing knowledge. Harvard:Harvard Business School Press. Retrieved from: www.staging.clearwater.asn.au

Wheeler, S. (2009). Learning space mashups: Combining web 2.0 tools to create collaborative and reflective learning spaces. Future Internet, 1(1), 3-13.

Xiao, L., Clark, S., Rosson, M.B. \& Caroll, J.M. (2008). Promoting reflective thinking in collaborative activities. Advanced Learning Technologies. Retrieved from:DOI: 10.1109/ICALT.2008.280

Yaacob, Walters, Md Ali, Shaik Abdullah \& Walters, T.(2014). Reflecting on Malaysian teacher trainees' journals. Malaysian Journal of Learning and Instruction, $11,1-21$.

Yaacob, A., Awang-Hashim, R., Valdez, N.P., \& Yusof, N. (2019). Illuminating diversity practices in Malaysian higher education institutions. Asia Pacific Journal of Educators and Education, 34, 1-16.

Yang, S. H. (2009). Using blogs to enhance critical reflection and community of practice. Journal of Educational Technology \& Society, 12(2), 11-21. 
Zuber-Skerritt, O. (2001). Action learning and action research: paradigm, praxis and programs. In Sankara, S., Dick, B. \& Passfield, R. (eds). Effective Change Management through Action Research and Action Learning: Concepts, Perspectives, Processes and Applications. Lismore, Australia: Cross University Press, 1-20. www.semanticscholar.org 